\title{
Study of Gamma-Ray Attenuation Coefficients of Some Glasses Containing CdO
}

\author{
G. S. M. Ahmed, A. S. Mahmoud, S. M. Salem, T. Z. Abou-Elnasr \\ Phys. Dept., Faculty of Science, Al-Azhar Univ., Cairo, Egypt
}

Email address:

Ahmedsaber334@gmail.com (A. S. Mahmoud)

To cite this article:

G. S. M. Ahmed, A. S. Mahmoud, S. M. Salem, T. Z. Abou-Elnasr. Study of Gamma-Ray Attenuation Coefficients of Some Glasses Containing CdO. American Journal of Physics and Applications. Vol. 3, No. 4, 2015, pp. 112-120. doi: 10.11648/j.ajpa.20150304.11

\begin{abstract}
Iron-phosphate glasses containing heavy metal cations are important material, especially when used to attenuate $\gamma$-ray and / or fast neutrons. Therefore, some glasses had been prepared, having the composition $\left[\left(70 \mathrm{~mol} \% \mathrm{P}_{2} \mathrm{O}_{5} .15 \mathrm{~mol} \%\right.\right.$ $\left.\mathrm{Na}_{2} \mathrm{O} .15 \mathrm{~mol} \% \mathrm{Fe}_{2} \mathrm{O}_{3}\right)+\mathrm{x} \mathrm{CdO}$, where $0 \leq \mathrm{x} \leq 30$ mole]. The melting temperature was $1200^{\circ} \mathrm{c}$ and the annealing temperature was $300^{\circ} \mathrm{c}$. The obtained solid glasses were then examined from $\gamma$-ray attenuation point of view, where both the linear and mass attenuation coefficients were studied for varying amounts of $\mathrm{CdO}$ and different $\gamma$-ray energies emitted from ${ }^{60} \mathrm{Co},{ }^{137} \mathrm{Cs}$ and ${ }^{152} \mathrm{Eu}$ radio-active sources. It was found that as $\mathrm{CdO}$ was gradually increased, the linear and mass attenuation coefficients increased gradually, while the half value layer decreased. On the other hand both linear and mass attenuation coefficients decreased and the half value layer increased as the energy of the incident $\gamma$-ray increased. Finally it can be concluded that these composition glasses can be used as good $\gamma$-ray shield especially at low gamma-ray energies.
\end{abstract}

Keywords: Linear Attenuation Coefficient, Mass Attenuation Coefficient, Glass

\section{Introduction}

Phosphate glasses are technologically important materials due to their interesting properties $[1,2]$, but their poor chemical durability limits their diverse uses. It was found that the addition of about 30 mol \% metal oxides (like $\mathrm{Fe}_{2} \mathrm{O}_{3}$ ) improve their chemical durability and attenuate $\gamma$-ray and fast neutrons [3-5]. However, iron - sodium - phosphate glasses were characterized by their high chemical durability, high thermal stability and low melting temperatures $[6,7]$.

On the other hand, a knowledge of gamma-ray attenuation parameters such as linear attenuation coefficient, mass attenuation coefficient and the half value layer is very important in the field of radiation physics protection and dosimetry. Accurate measured values of these parameters are required in many scientific and industrial applications. In the design of shielding materials, the linear attenuation coefficient $(\mu)$ (which is defined as the probability of radiation interacting with a material per unit path length), is an important parameter and its magnitude depends on the incident photon energy, the atomic number and the density $(\rho)$ of such material [8]. Also, the mass attenuation coefficient $\left(\mu_{\mathrm{m}} \mathrm{cm}^{2} \cdot \mathrm{g}^{-1}\right)$ measures directly the effectiveness of a shielding material. Generally, the calculations of the mass attenuation coefficient at different $\gamma$-ray energies are widely needed and used as a radiation shielding design parameter [9].

The object of this paper is to determine the linear attenuation coefficients $(\mu)$, mass attenuation coefficients $\left(\mu_{\mathrm{m}}\right)$ and half value layer (HVL) of some sodium iron phosphate glasses obeying the composition $15 \mathrm{~mol} \% \mathrm{Na}_{2} \mathrm{O} .15 \mathrm{~mol} \%$ $\mathrm{Fe}_{2} \mathrm{O}_{3} .70 \mathrm{~mol} \% \mathrm{P}_{2} \mathrm{O}_{5} . \mathrm{x} \mathrm{CdO}$, where $\mathrm{CdO}$ was introduced in elevated amounts $(\mathrm{x}=5,10,15,20,25$ and 30 mole $)$ by addition.

\section{Experimental Work}

Analytically pure grade chemicals were used to prepare the supposed glass samples. The batch mixtures were melted in porcelain crucibles at $1200^{\circ} \mathrm{C}$ for $2 \mathrm{~h}$ until homogeneous glasses were obtained. The melts were then poured on a copper plate at room temperature and the obtained solid glasses were then annealed at $300^{\circ} \mathrm{C}$ and the oven was turned off and was left to cool to room temperature, in order to remove any internal stresses. The obtained samples were polished to obtain square samples of $1 \mathrm{~cm}$ edge and $1 \mathrm{~mm}$ thickness.

The density was measured at room temperature using the standard Archimedes method, with toluene as the immersion fluid of stable density at room temperature $\left(0.866 \mathrm{~g} / \mathrm{cm}^{3}\right)$. 
IR absorption spectra of the studied glass were measured at RT in the range $(4000-400) \mathrm{cm}^{-1}$ by using a Fourier Transform Infra-red spectrometer (type Perken Elmer, model RTX). KBr disc technique was used, where $2 \mathrm{mg}$ of the sample under test was weighted and mixed well with about $200 \mathrm{mg} \mathrm{KBr}$ and was then pressed to obtain disk shape sample suitable for IR measurement.

Attenuation coefficients of the studied glass system were measured in a narrow beam transmission geometry. The experimental setup of such geometry is exhibited in Fig. (1), as outlined in Ref. [10], was used in the present work. . A 3" x 3 " NaI (TI) crystal detector with energy resolution of $6.7 \%$ under good geometry condition in conjunction with multichannel analyzer (MCA) were used.

The examined sample was placed in the specimen holder at a distance of $4 \mathrm{~cm}$ from the source. The distance between source and detector was $7 \mathrm{~cm}$. A ${ }^{60} \mathrm{Co}$ source of activity 6.9 $\mu \mathrm{Ci},{ }^{137} \mathrm{Cs}$ source of activity $10 \mu \mathrm{Ci}$ and ${ }^{152} \mathrm{Eu}$ source of activity $3.9 \mu \mathrm{Ci}$ were used for different photon energies. Incident and transmitted intensities of photons were measured using the MCA for fixed time for all samples, by selecting an arrow region symmetrical with respect to the centroid of the photo peak.

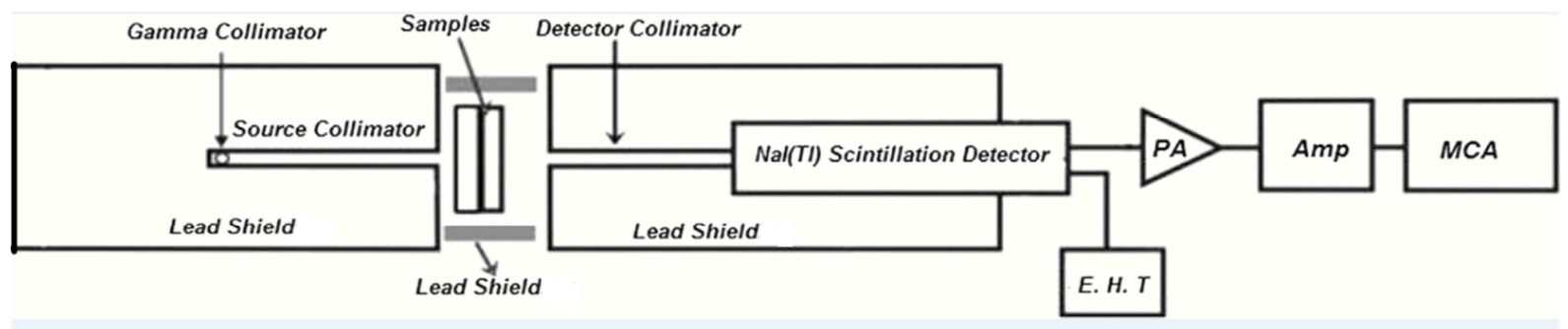

Fig. (1). Experimental setup of the used narrow beam transmission geometry [10].

\section{Results and Discussion}

The visual examination of all glasses after annealing showed that all samples exhibit amorphous nature. The internal structure and the building groups of these glasses were firstly examined applying infra-red analyses.

Fig. (2), shows the obtained IR spectra in the range from 400 to $4000 \mathrm{~cm}-1$ for all the studied glasses.

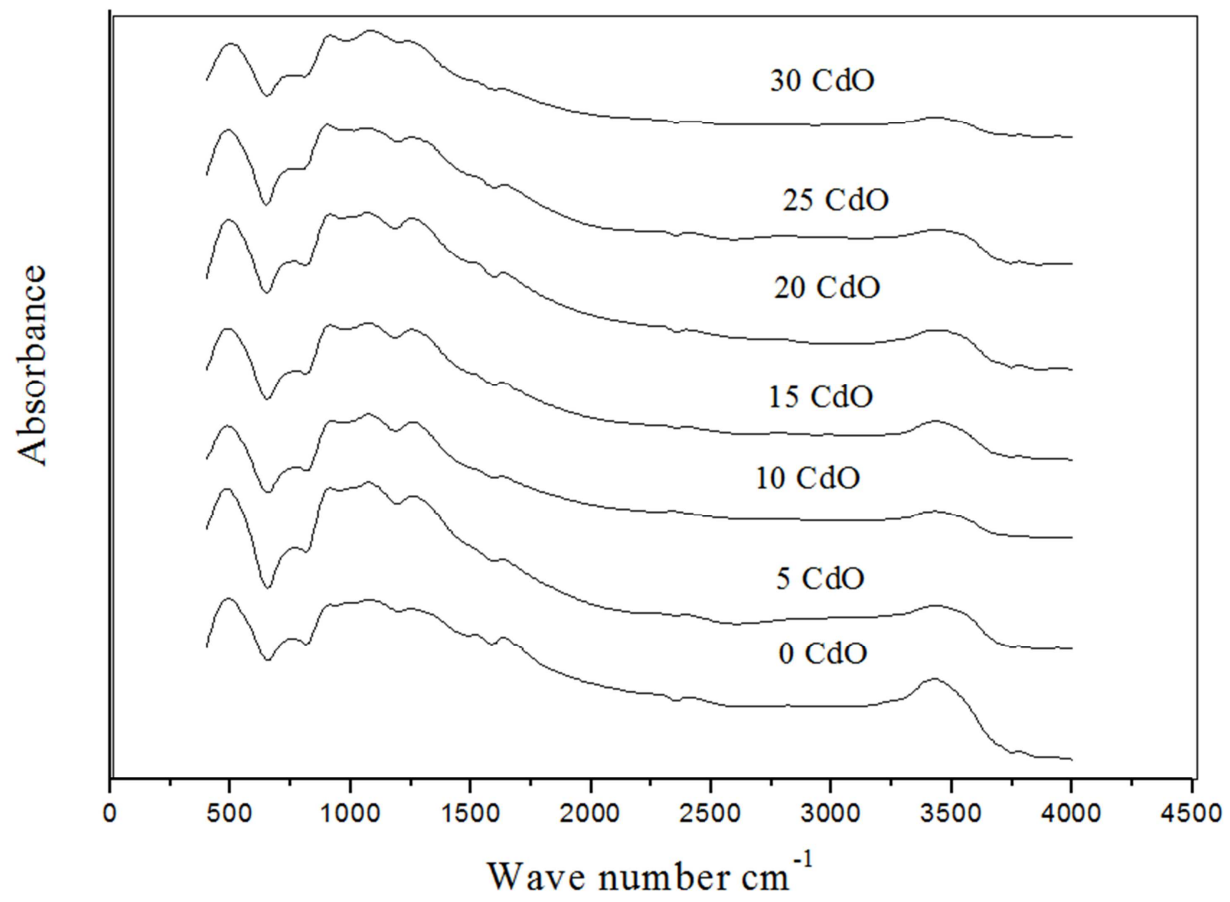

Fig. (2). The as measured IR spectra of all samples.

This figure reveals that the range of interest is in between 400 and $2000 \mathrm{~cm}^{-1}$ only, since it is known that all the bands appeared in the range from 2200 to $4000 \mathrm{~cm}^{-1}$ can be attributed to $\mathrm{H}_{2} \mathrm{O}, \mathrm{H}-\mathrm{O}-\mathrm{H}$ and hydrogen-bond vibrations. Also the band appeared in between $1600 \mathrm{~cm}^{-1}$ and $1770 \mathrm{~cm}^{-1}$ in all glasses can be attributed to the stretching vibration of $\mathrm{H}-\mathrm{O}$ bond. The appearance of these bands evidenced the presence of some $-\mathrm{OH}$ and $\mathrm{H}-\mathrm{O}-\mathrm{H}$ groups, which may be due the used $\mathrm{KBr}$ disk technique [11-13].

Accordingly, the range from 400 to $2000 \mathrm{~cm}^{-1}$ was 
thoroughly examined by applying the deconvolution program to extract as really as possible the correct IR bands. However Fig. (3), shows the deconvoluted spectrum of sample no. (4), that contains $15 \mathrm{~mol} \mathrm{CdO}$ as representative figure. All other samples show approximately similar IR spectra.

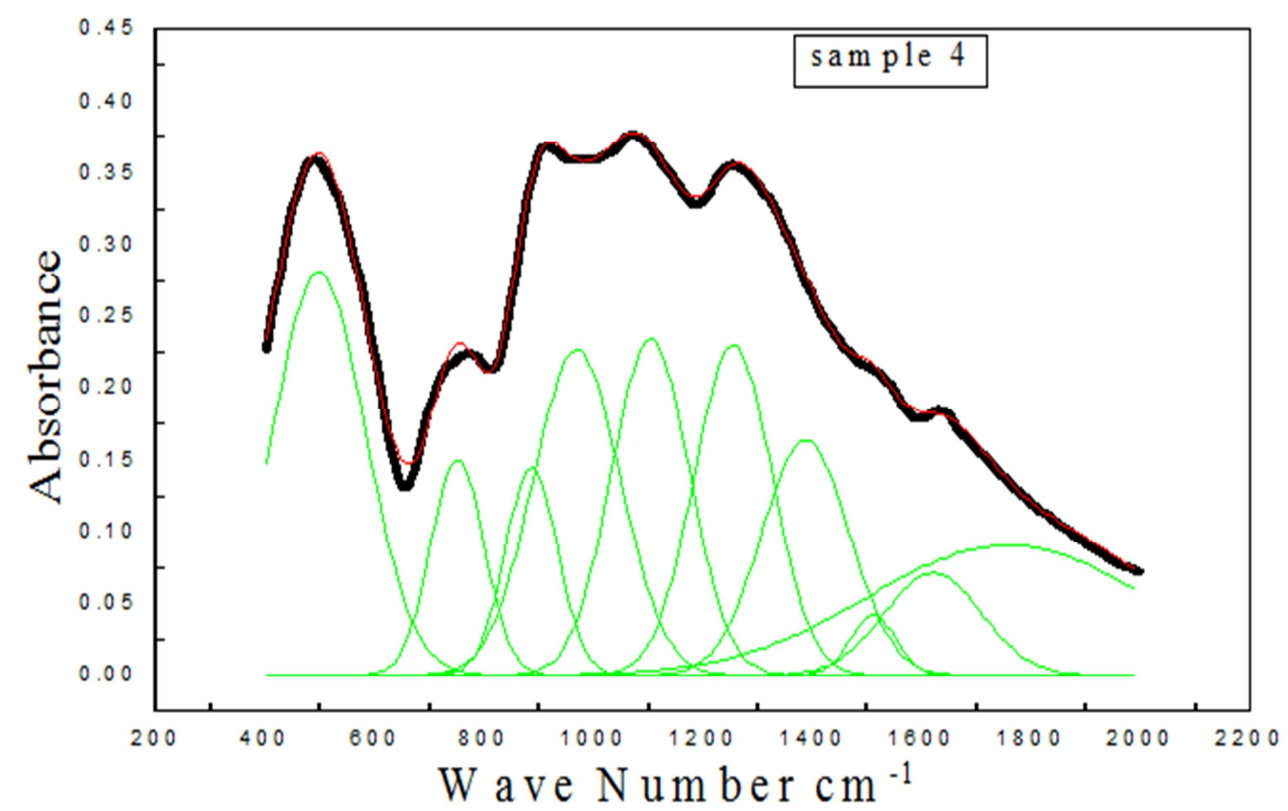

Fig. (3). The deconvoluted spectrum of sample no. (4), that contains $15 \mathrm{~mol} \mathrm{CdO}$, as representative figure.

It was found that some major IR bands appeared in the recorded spectra and they are listed in Table (1).

Table (1). Frequency ranges characteristic of the obtained IR spectra of the studied glasses.

\begin{tabular}{|c|c|c|c|c|c|c|c|}
\hline $30 \mathrm{~mol} \mathrm{CdO}$ & $25 \mathrm{~mol} \mathrm{CdO}$ & $20 \mathrm{~mol} \mathrm{CdO}$ & $15 \mathrm{~mol} \mathrm{CdO}$ & $10 \mathrm{~mol} \mathrm{CdO}$ & $5 \mathrm{~mol} \mathrm{CdO}$ & $0 \mathrm{~mol} \mathrm{CdO}$ & Number of peaks \\
\hline 505 & 496 & 502 & 497 & 492 & 488 & 502 & 1 \\
\hline 738 & 735 & 732 & 749 & 753 & 750 & 749 & 2 \\
\hline 900 & 872 & 893 & 885 & 891 & 879 & 882 & 3 \\
\hline 942 & 960 & 937 & 968 & 959 & 961 & 953 & 4 \\
\hline 1104 & 1105 & 1100 & 1102 & 1092 & 1091 & 1084 & 5 \\
\hline 1259 & 1264 & 1251 & 1253 & 1250 & 1248 & 1265 & 6 \\
\hline 1391 & 1399 & 1387 & 1386 & 1392 & 1389 & 1443 & 7 \\
\hline 1511 & 1520 & 1525 & 1510 & 1512 & 1506 & 1522 & 8 \\
\hline 1629 & 1643 & 1648 & 1619 & 1624 & 1625 & 1650 & 9 \\
\hline 1763 & 1742 & 1762 & 1757 & 1729 & 1770 & 1759 & 10 \\
\hline
\end{tabular}

These bands can be attributed to the vibration of the following, structural groups or bond vibrations,

1- The band appeared between 488 and $505 \mathrm{~cm}^{-1}$ in all glasses may be due to two overlapped bands, the first one indicated the presence of some iron ions in the octahedral coordination state $\left(\mathrm{FeO}_{6}\right)$ occupying glass network modifier positions [14], the second one may be due to Cd-O stretching vibration [15].

2- The band appeared between 732 and $753 \mathrm{~cm}^{-1}$ in all glasses can be attributed to the symmetric stretching vibration of $\mathrm{P}-\mathrm{O}-\mathrm{P}$ bond $[16,17]$.

3- The band appeared between 872 and $900 \mathrm{~cm}^{-1}$ in all glasses, can be assigned to the asymmetric stretching vibration of P-O-P bond in $\mathrm{Q}^{1}$ speeches [18].

4- The band appeared between 937 and $968 \mathrm{~cm}^{-1}$, can be assigned to the $\mathrm{PO}_{3}$ vibration and/or the vibration of $\left(\mathrm{PO}_{4}\right)^{3-}$ structural group in $\mathrm{Q}^{\mathrm{o}}$ speeches $[19,20]$.

5- The band appeared between 1084 and $1105 \mathrm{~cm}^{-1}$ in all glasses can be assigned to the symmetric stretching vibration of $\mathrm{PO}_{2}$ as well as the vibration of $(\mathrm{P}-\mathrm{O})^{-}$ groups in $\mathrm{Q}^{\mathrm{o}}$ speeches[21].

6- The band appeared between 1248 and $1264 \mathrm{~cm}^{-1}$ in all glasses, can be correlated to the symmetric stretching vibration of two non-bridge oxygen atoms bonded to a phosphorus atom $\left(\mathrm{PO}_{2}\right)$ unit $(\mathrm{O}-\mathrm{P}-\mathrm{O})$ and / or the $\mathrm{O}=\mathrm{P}$ in $\mathrm{Q}^{2}$ units [22].

7- The band appeared between 1386 and $1443 \mathrm{~cm}^{-1}$ in all glasses, can be assigned to the asymmetric stretching vibration modes of the non-bridging oxygen atom bonded to phosphorus atom and/or the vibration of $\mathrm{P}=\mathrm{O}$ 
bond in $\mathrm{Q}^{2}$ speeches [23].

8- The band appeared between 1506 and $1525 \mathrm{~cm}^{-1}$ can be assigned to the vibration of the present molecular water or hydroxyl-related bonds [11].

The IR results indicated that many structural groups due to phosphorus ions appeared such as $\mathrm{P}=\mathrm{O}, \mathrm{PO}_{2}, \mathrm{PO}_{4} \ldots$....etc in different $\mathrm{Q}^{\mathrm{n}}$ speeches. All the present sodium and iron ions as well as all the introduced cadmium ions participate in the glass networks as glass network modifiers. That is both bridging and non - bridging oxygen anions are present in the glass networks of the studied glasses.

Gamma ray with different energies in the range from 121.8 to $1407.9 \mathrm{keV}$ were used to study the attenuation coefficients parameters for the investigated glass compositions.

${ }^{60} \mathrm{Co}(1173.2$ and $1332.5 \mathrm{keV}),{ }^{137} \mathrm{Cs}(661.6 \mathrm{keV})$ and ${ }^{152} \mathrm{Eu}$ (121.8, 244.7, 344.2, 778.9, 964, 1086.4, $1407.9 \mathrm{keV})$ gamma-ray sources were used in this study. The measured intensities of the $\gamma$-ray transmitted through glassy barriers are presented on semi-log scale as a function of the barrier thickness at an incident $\gamma$-ray energy of $121.8 \mathrm{KeV}$ (Fig. 4).

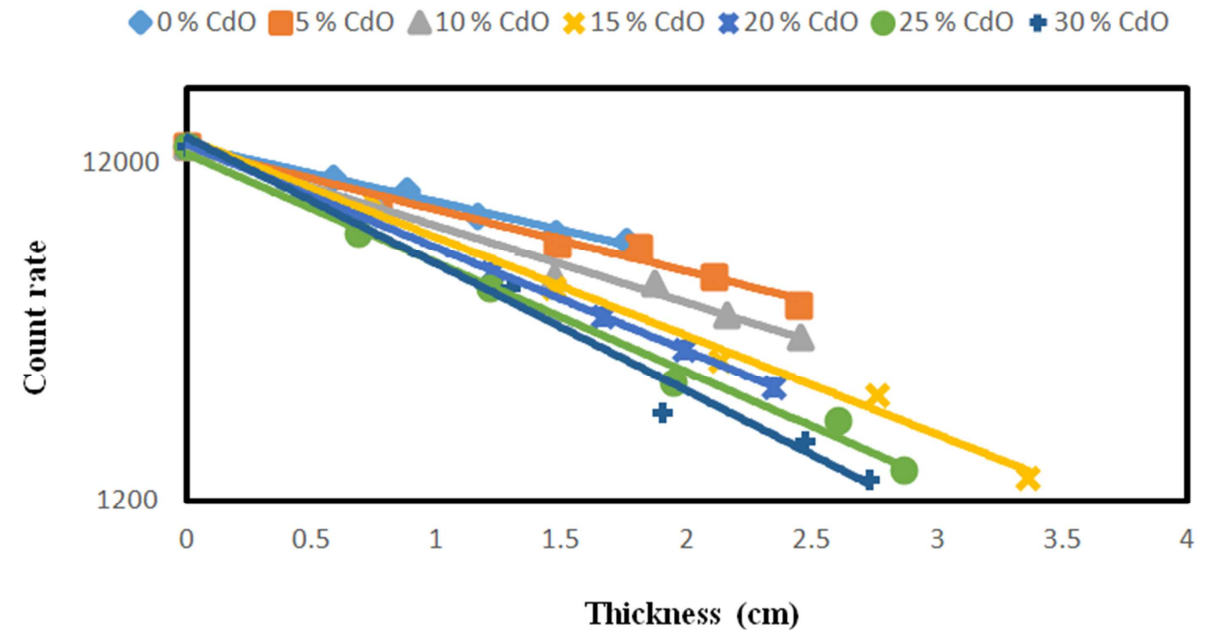

Fig. (4). Count rate as a function of the barrier thickness at an incident $\gamma$-ray energy of $121.8 \mathrm{KeV}$ as representative figure.

It can be noticed from Fig.(4) that, the intensity of the $\gamma$ ray decreases exponentially with increasing the barrier thicknesses. The straight lines are due to the obtained log values of the measured $\gamma$-ray intensities. The slope values of these lines were used to determine the linear attenuation coefficients $(\mu)$ in $\mathrm{cm}^{-1}$ using the following equation [24],

$$
\mathrm{I}=\mathrm{I}_{0} \mathrm{e}^{-\mu \mathrm{x}}
$$

The values of the linear attenuation coefficients of all $\gamma$-ray energies are plotted versus $\mathrm{CdO}$ concentration, and Fig. (5) is a representative figure of the values of the linear attenuation coefficient at $121.8 \mathrm{keV}$.

It was shown that the linear attenuation coefficient for all glass barriers increased with increasing $\mathrm{CdO}$ concentration at all $\gamma$-ray energies. From another point of view the linear attenuation coefficients as a function of $\gamma$-ray energies for different $\mathrm{CdO}$ concentrations are shown in Fig. (6.a), where it shows gradual exponential decrease and it tends to be stable at about $1100 \mathrm{KeV}$ photon energy. The behavior is clearly observed from Fig. (6.b) that represent the obtained values for sample containing zero $\mathrm{CdO}$.

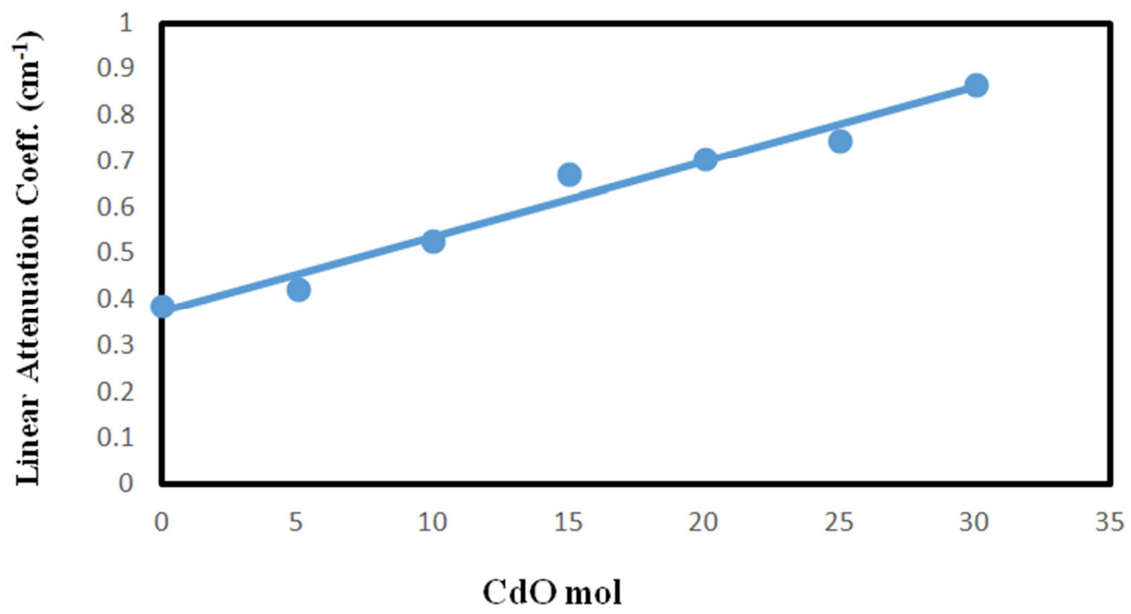

Fig. (5). The variation of the linear attenuation coefficient of $\gamma$-rays at $121.8 \mathrm{keV}$ versus $C d O$ concentration, as representative figure. 

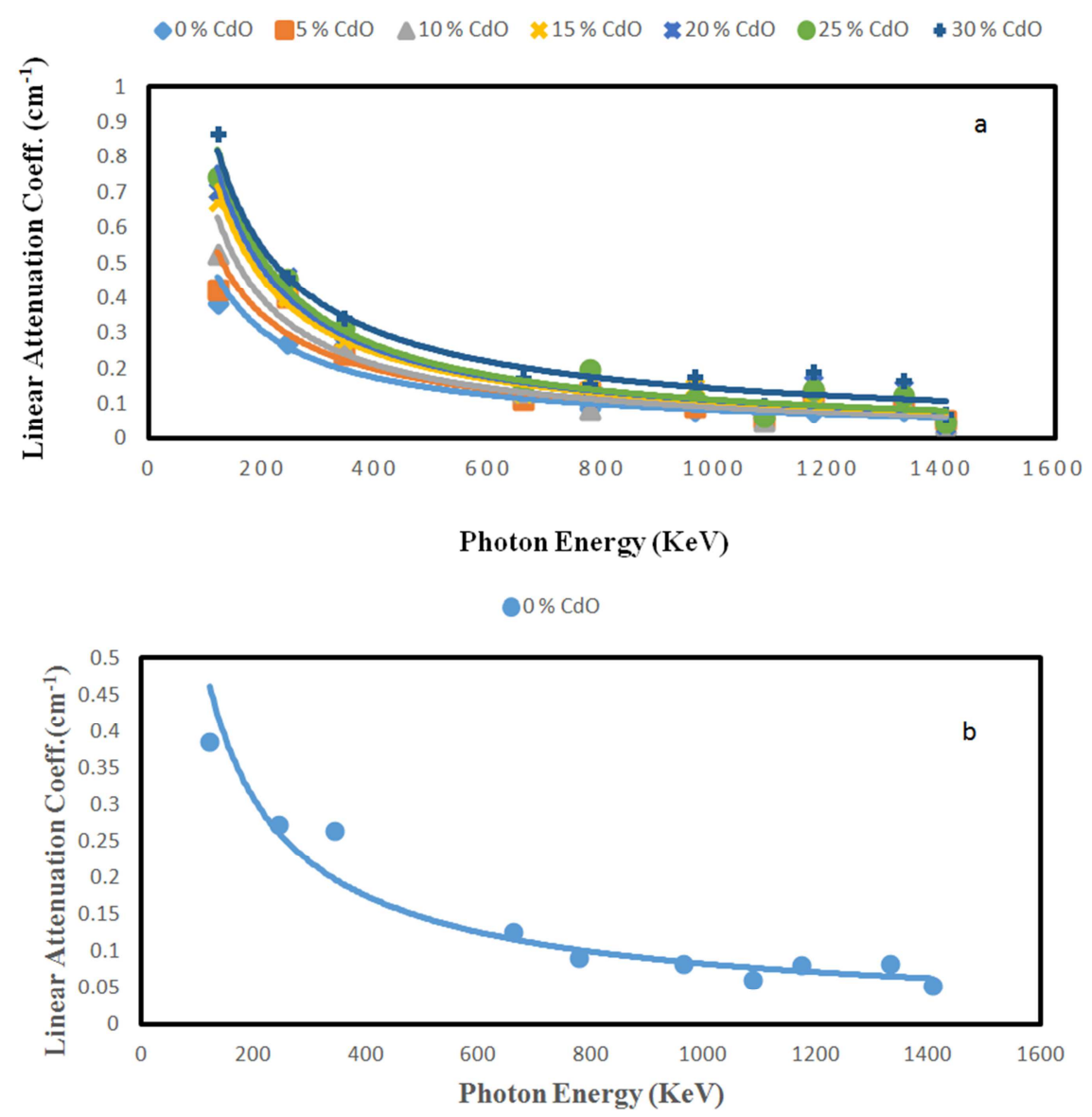

Fig. (6). The variation of the linear attenuation coefficients as a function of $\gamma$-ray energies.

It was observed that a sharp decrease in the linear attenuation coefficients takes place with the increase of gamma ray energy from 121.8 to $344.27 \mathrm{keV}$. That could be explained because in these energy region the reaction between the glasses sample barriers and gamma ray is only due to the photoelectric effect. In the region of 661.6-1407.9 $\mathrm{KeV}$, a slight decrease in the linear attenuation coefficients was seen due to the fact that the reaction in this region is Compton scattering or may be due to both photoelectric effect and Compton scattering reactions.

The mass attenuation coefficients can be calculated from the following equation [5],

$$
\mu_{\mathrm{m}}=\mu / \rho_{\exp }
$$

where $\mu_{\mathrm{m}}$ is the mass attenuation coefficient, $\mu$ is the linear attenuation cofficient and $\rho_{\exp }$ is the density of the sample under study. Accordingly, the density of all samples must be measured.

The experimental density values $\left(\rho_{\text {exp }}\right)$ of the studied glasses has been measured and calculated applying the liquid displacement method using Archimedes formula,

$$
\rho_{\text {exp }}=\left(\frac{w_{a}}{w_{a}-w_{t}}\right) \times \rho_{t}
$$

Where $\mathrm{w}_{\mathrm{a}}$ and $\mathrm{w}_{\mathrm{t}}$ is the weights of the sample in air and in liquid respectively and $\rho_{t}$ is the density of the used liquid [25].

The obtained density values for all glass samples are listed in Table (2), as function of $\mathrm{CdO}$ content.

Table (2). the change in density as a function of $C d O$ content.

\begin{tabular}{llllllll}
\hline $\begin{array}{l}\text { CdO mol } \\
(\rho)_{\exp }\end{array}$ & 0 & 5 & 10 & 15 & 20 & 25 & 30 \\
$\left(\mathrm{gm} / \mathrm{cm}^{3}\right)$ & 2.71 & 2.80 & 2.90 & 2.99 & 3.07 & 3.14 & 3.23 \\
\hline
\end{tabular}

From the table, it could be seen that the density values increased gradually with the gradual increase of CdO. Such increase can be attributed to the high density value of $\mathrm{CdO}$ $\left(8.15 \mathrm{~g} / \mathrm{cm}^{3}\right)$ which is greater than the density of $\mathrm{Na}_{2} \mathrm{O}(2.27$ $\left.\mathrm{g} / \mathrm{cm}^{3}\right), \mathrm{Fe}_{2} \mathrm{O}_{3}\left(5.242 \mathrm{~g} / \mathrm{cm}^{3}\right)$ and $\mathrm{P}_{2} \mathrm{O}_{5}\left(2.39 \mathrm{~g} / \mathrm{cm}^{3}\right)$. So when $\mathrm{CdO}$ was added in elevated amounts for the studied glass system, the density will logically increased.

The values of the mass attenuation coefficients at different $\gamma$-ray energies are plotted versus $\mathrm{CdO}$ concentration as shown in Fig.s (7, 8 and 9) respectively. The obtained values are listed in Table (3). 


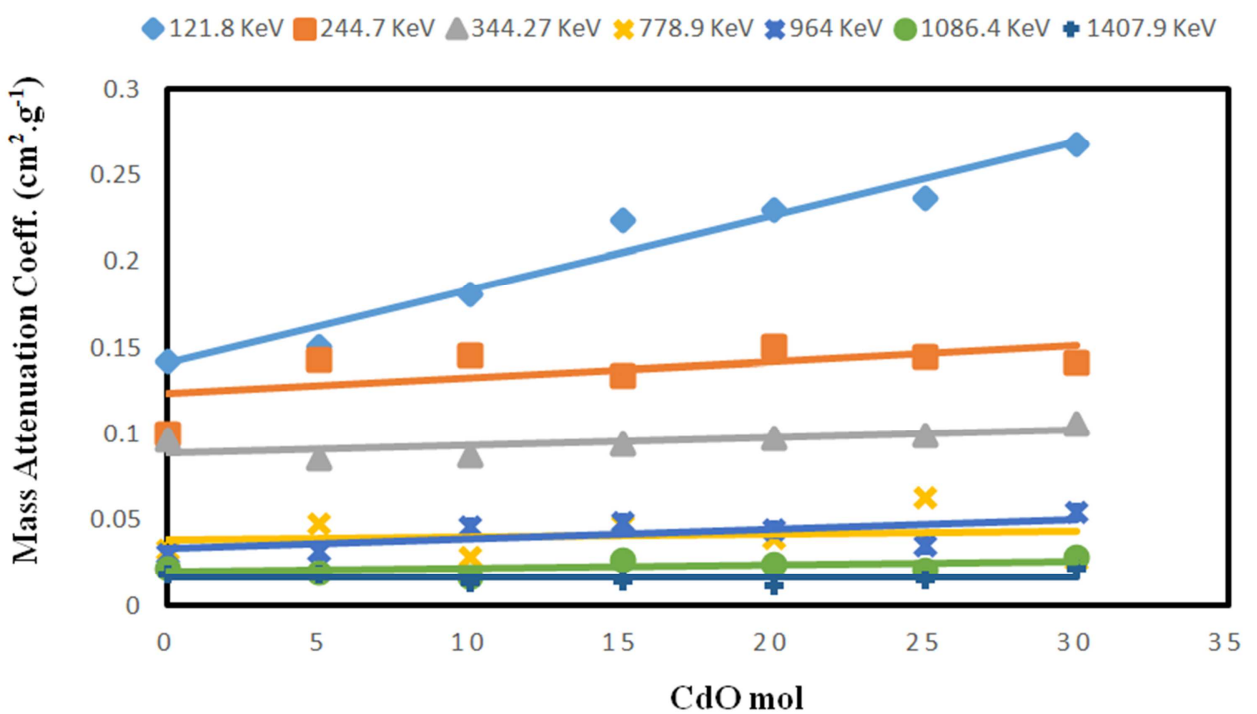

Fig. (7). The variation of the mass attenuation coefficient values of $\gamma$-ray emitted from ${ }^{152}$ Eu radioactive source for different concentrations of CdO.

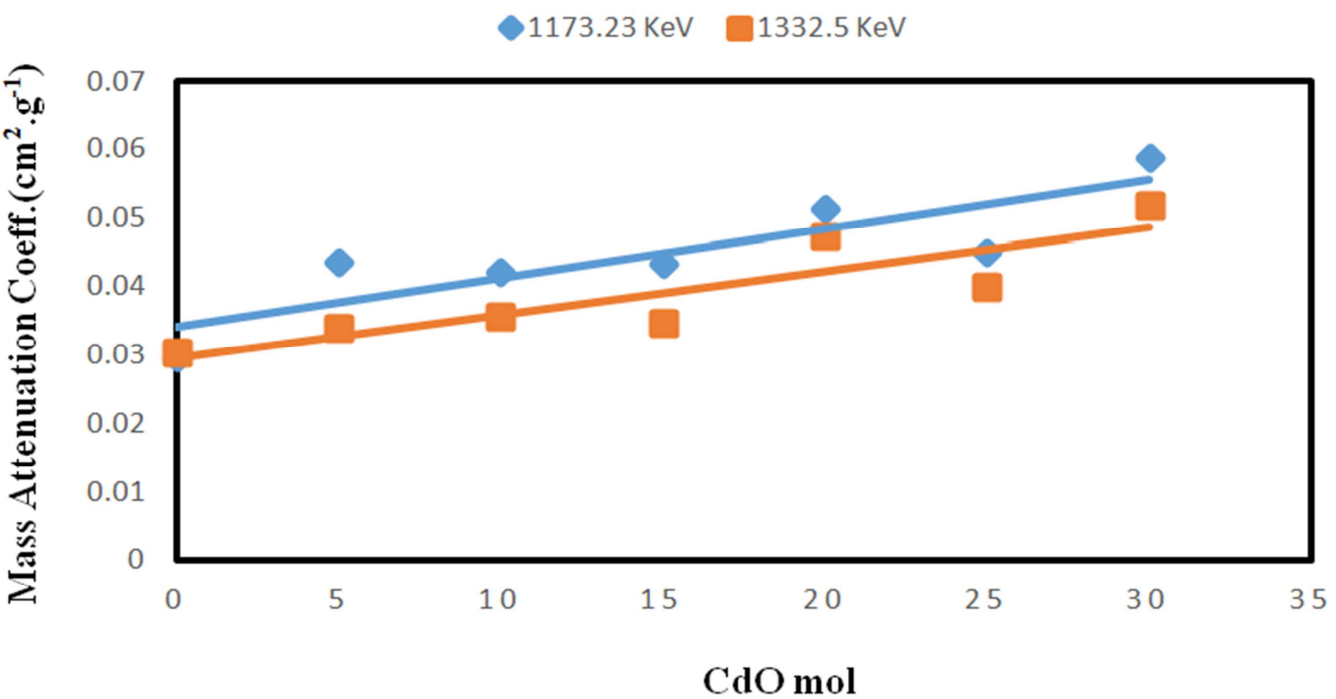

Fig. (8). The variation of the mass attenuation coefficient values of $\gamma$-ray emitted from ${ }^{60} \mathrm{Co}$ radioactive source for different concentrations of CdO.

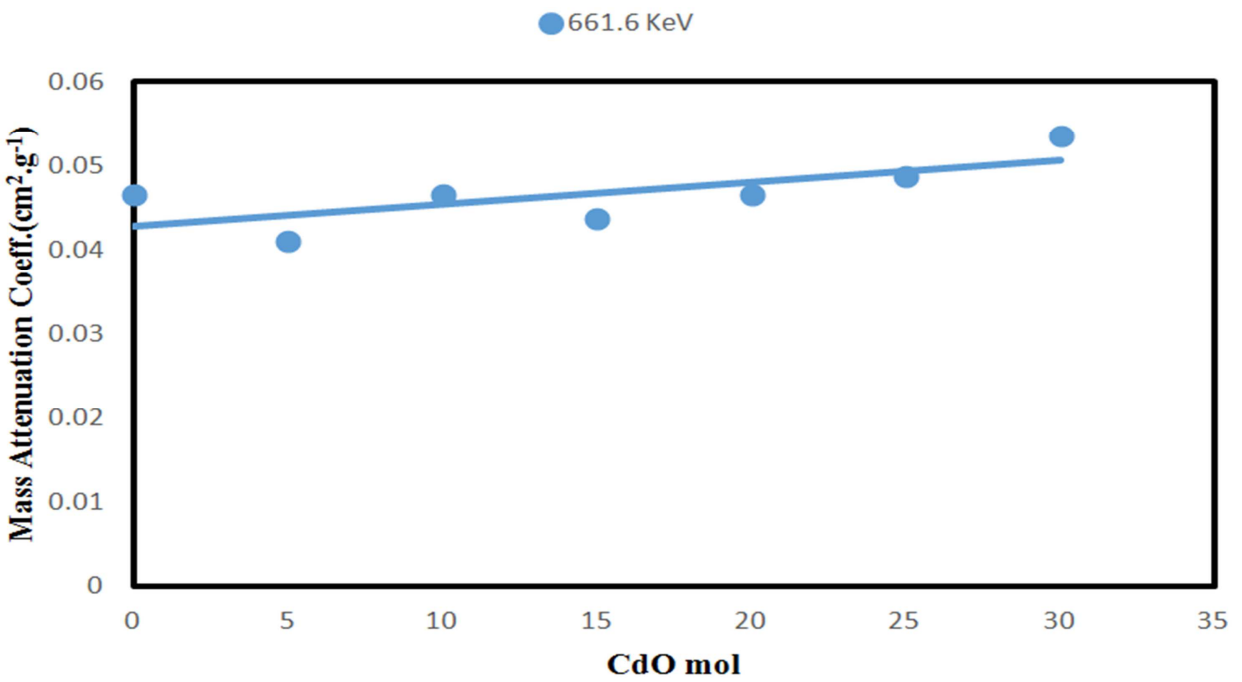

Fig. (9). The variation of the mass attenuation coefficient values of $\gamma$-ray emitted from ${ }^{137} C$ s radioactive source for different concentrations of CdO. 
Table (3). The mass attenuation coefficient values of all glasses sample with different $\gamma$-ray energies.

\begin{tabular}{|c|c|c|c|c|c|c|c|c|c|c|}
\hline \multirow{3}{*}{$\begin{array}{l}\text { Energy KeV } \\
\text { CdO mol }\end{array}$} & \multicolumn{10}{|c|}{$\mu_{\text {mass }}\left(\mathrm{cm}^{2} \cdot \mathrm{g}^{-1}\right)$} \\
\hline & \multirow{2}{*}{121.8} & \multirow{2}{*}{244.7} & \multirow{2}{*}{344.27} & \multirow{2}{*}{661.6} & \multirow{2}{*}{778.9} & \multirow{2}{*}{964} & \multirow{2}{*}{1086.4} & \multirow{2}{*}{1173.23} & \multirow{2}{*}{1332.5} & \multirow{2}{*}{147.9} \\
\hline & & & & & & & & & & \\
\hline 0 & 0.143 & 0.101 & 0.098 & 0.047 & 0.033 & 0.030 & 0.023 & 0.030 & 0.030 & 0.019 \\
\hline 5 & 0.151 & 0.143 & 0.086 & 0.041 & 0.048 & 0.033 & 0.020 & 0.044 & 0.034 & 0.019 \\
\hline 10 & 0.182 & 0.146 & 0.088 & 0.047 & 0.029 & 0.047 & 0.017 & 0.042 & 0.036 & 0.014 \\
\hline 15 & 0.225 & 0.134 & 0.095 & 0.044 & 0.048 & 0.049 & 0.027 & 0.043 & 0.035 & 0.015 \\
\hline 20 & 0.231 & 0.151 & 0.099 & 0.047 & 0.040 & 0.045 & 0.025 & 0.052 & 0.047 & 0.012 \\
\hline 25 & 0.238 & 0.145 & 0.100 & 0.049 & 0.063 & 0.036 & 0.021 & 0.045 & 0.040 & 0.015 \\
\hline 30 & 0.268 & 0.142 & 0.106 & 0.054 & 0.049 & 0.055 & 0.029 & 0.059 & 0.052 & 0.023 \\
\hline
\end{tabular}

It can be observed from this table that the mass attenuation coefficient exhibits approximately gradual increase as $\mathrm{CdO}$ was increased, but it shows approximately gradual decrease as the $\gamma$-ray energy was increased. This behavior showed a good confirmation that the introduced $\mathrm{CdO}$ act to increase the mass attenuation coefficient. It appeared also that the studied glass sample exhibit high efficiency at low photon energies and their efficiency decreased as $\gamma$-ray energy increased [26].

The mass attenuation coefficients as a function of $\gamma$-ray energies for different $\mathrm{CdO}$ concentrations are represented in Fig. (10).

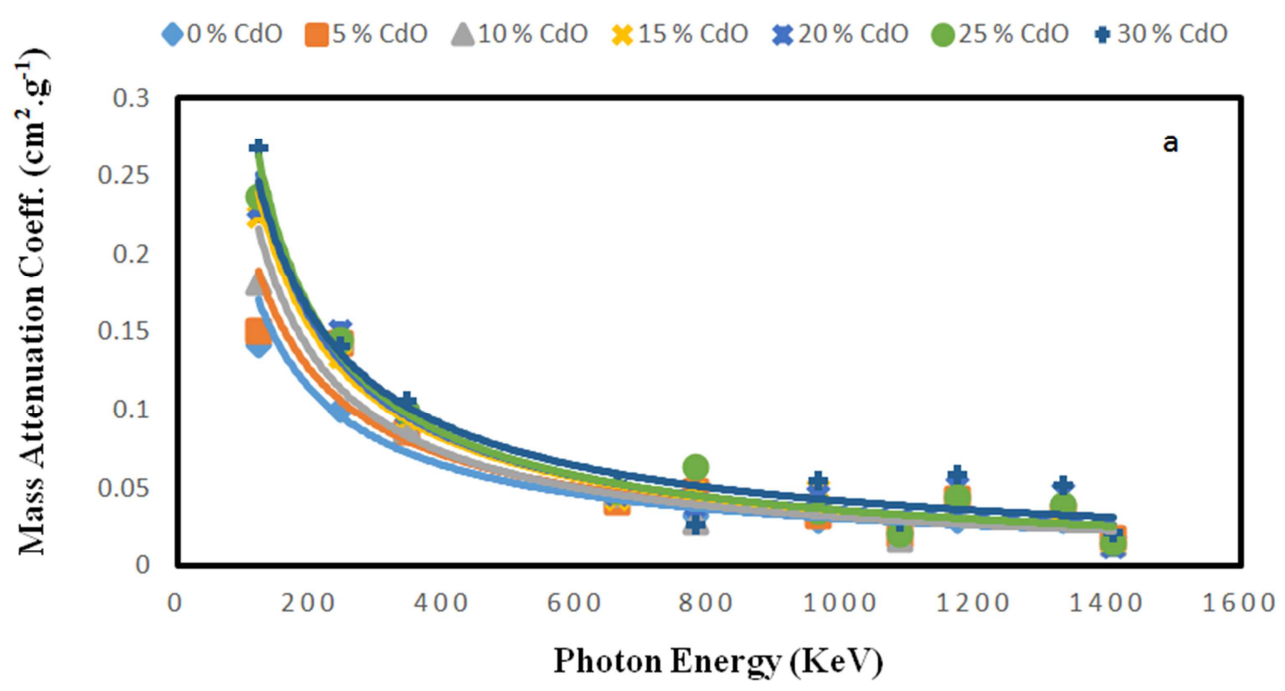

$\bullet 0 \% \mathrm{CdO}$

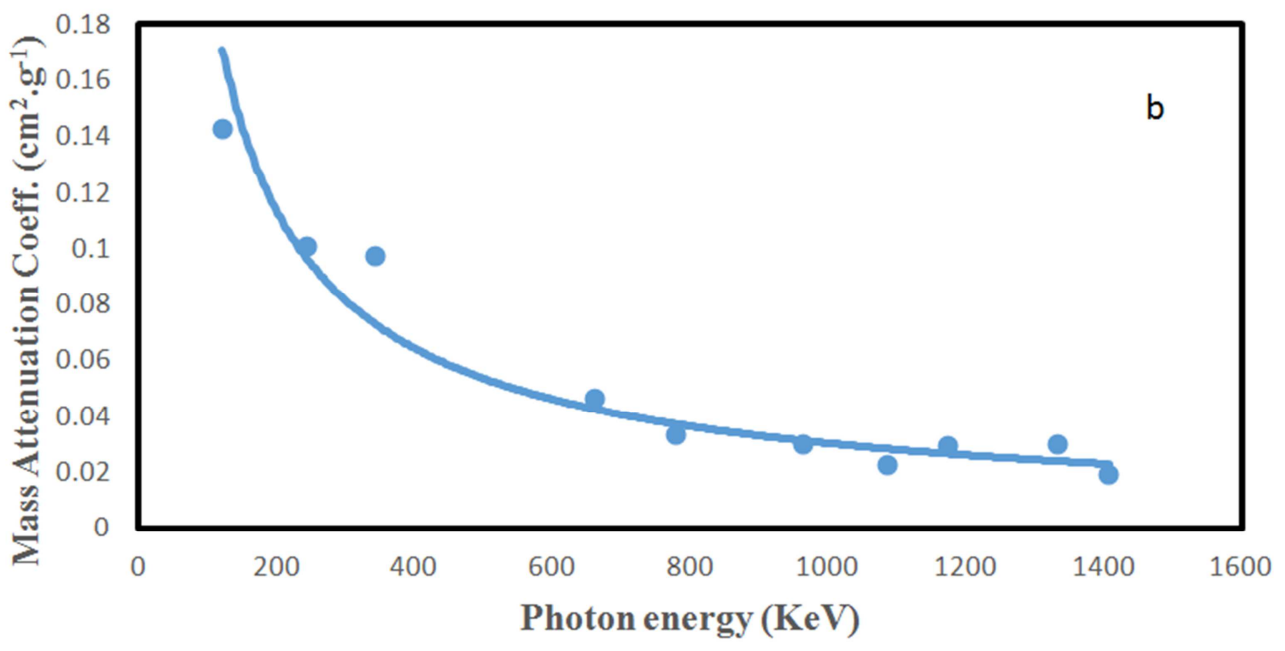

Fig. (10). The variation of the mass attenuation coefficients as a function of $\gamma$-ray energies.

The Half value layer (HVL) of the studied glasses was also calculated from the following equation [27],

$$
\mathrm{X}_{1 / 2}=\ln 2 / \mu
$$

where $\mathrm{X}_{1 / 2}$ is the HVL and $\mu$ is the linear attenuation coefficient.

The values of the HVL are listed in the Table (4). 
Table (4). Half value layer (HVL) of all samples.

\begin{tabular}{|c|c|c|c|c|c|c|c|c|c|c|}
\hline & \multicolumn{10}{|c|}{ HVL (cm) } \\
\hline Energy $\mathrm{KeV}$ & \multirow{2}{*}{121.8} & \multirow{2}{*}{244.7} & \multirow{2}{*}{344.27} & \multirow{2}{*}{661.6} & \multirow{2}{*}{778.9} & \multirow{2}{*}{964} & \multirow{2}{*}{1086.4} & \multirow{2}{*}{1173.23} & \multirow{2}{*}{1332.5} & \multirow{2}{*}{147.9} \\
\hline CdO mol & & & & & & & & & & \\
\hline 0 & 1.796 & 2.539 & 2.626 & 5.501 & 7.702 & 8.453 & 11.363 & 8.664 & 8.453 & 13.330 \\
\hline 5 & 1.643 & 1.729 & 2.876 & 6.027 & 5.134 & 7.617 & 12.378 & 5.682 & 7.296 & 13.330 \\
\hline 10 & 1.315 & 1.635 & 2.729 & 5.134 & 8.155 & 5.134 & 13.863 & 5.682 & 6.730 & 16.906 \\
\hline 15 & 1.030 & 1.724 & 2.441 & 5.291 & 4.847 & 4.683 & 8.453 & 5.332 & 6.665 & 15.753 \\
\hline 20 & 0.980 & 1.497 & 2.295 & 4.847 & 5.682 & 5.023 & 9.120 & 4.387 & 4.780 & 18.241 \\
\hline 25 & 0.930 & 1.520 & 2.215 & 4.530 & 3.483 & 6.134 & 10.502 & 4.916 & 5.545 & 14.441 \\
\hline 30 & 0.799 & 1.513 & 2.015 & 4.007 & 4.415 & 3.894 & 7.296 & 3.648 & 4.126 & 9.495 \\
\hline
\end{tabular}

The obtained HVL's exhibited in this table show a gradual decrease as $\mathrm{CdO}$ was increase, while shows gradual increase as the $\gamma$-ray energy was gradual increase. It is seen that all the obtained results confirm each other and the change in the obtained values of $\mu$ and $\mu_{\mathrm{m}}$ as well as HVL appeared to be as expected [28].

\section{Conclusion}

Sodium - iron - phosphate glasses containing varying amount of $\mathrm{CdO}$ were thoroughly investigated to attenuate different gamma-ray energies. The investigation of $\gamma$-ray attenuation values showed that, as $\mathrm{CdO}$ was gradually increased, the linear and mass attenuation coefficients increased gradually, while the half value layer decreased. On the other hand, as the $\gamma$-ray energy was increased both linear and mass attenuation coefficients decreased, while the half value layers increased. It can be concluded that these glasses system could be used as $\gamma$-ray shield especially at low gamma-ray energies. The sample containing $30 \mathrm{~mol} \mathrm{CdO}$ is the preferable $\gamma$-ray shielding material among the studied samples.

\section{References}

[1] Sang Hyeok Im, Young Hoon Na, Nam Jin Kim, Dong Hwan Kim, Cha Won Hwang and Bong Ki Ryu, Thin Solid Films, 518 (24) (2010) 46.

[2] J. A. Wilder, J. Non-Cryst, Solids, 38-39 (1980) 879.

[3] X. Fang, C. S. Ray, A. Mogus-Milankovic and D. E. Day, J. Non-Cryst. Solids, 283 (2001) 162.

[4] P. A. Bingham, R. J. Hand, S. D. Forder and A. Lavaysierre, J. Hazard. Mater. (B), 122 (2005) 129.

[5] H. A. Saudi, A. G. Mostafa, N. Sheta, S. U. ElKameesy and H. A.Sallam, J. Physica (B), 406 (2011) 4001.

[6] P. A. Bingham, R. J. Hand and S. D. Forder, Mater. Res. Bull., 41 (2006) 1622.

[7] P. A. Bingham, R. J. Hand, S. D. Forder, A. Lavaysierre, F. Deloffre, S. H. Kilcoyne and I. Yasin, Eur. J. Glass Sci. Technol. (B), 47 (2006) 313.

[8] J.Wood, "Computational Methods in Reactor Shielding",
Pergamon Press, Inc., NewYork, (1982).

[9] M. F. Kaplan," Concrete Radiation Shielding", John Wiley \& Sons, New York, (1989).

[10] Aly Saeed, R. M. El shazly, Y. H. Elbashar, A. M. Abou Elazm, M. M. El-Okr, M. N. H. Comsan, A. M. Osman, A. M. Abdal-monem and A. R. El-Sersy, J. Radiation Physics and Chemistry, 102 (2014) 167.

[11] S. A. MacDonald, C. R. Schardt, D. J. Masiello and J. H. Simmons, J. Non-Cryst. Solids, 275 (2000) 72.

[12] A. A. Akatov, B. S. Nikonov, B. I. Omelyanenko, S. V. Stefanovsky and J. C. Marra, Phys. Chem. Glasses, 35 (2009) 245 .

[13] M. S. Aziz, F. Abdel-Wahab, A. G. Mostafa and E. M. El Agwany, J. Mater. Chem. Phys., 91 (2005) 532.

[14] B. Bridge and N. D. Patel, J. Non- Cryst. Solids, 91 (1987) 27.

[15] R. Srinivasaraghavan, R. Chandiramouli, B.G. Jeyaprakash and S. Seshadri, J. Spectrochimica Acta, 102 (2013) 242.

[16] Y. M. Moustaffa and K. El-Egili, J. Non-Cryst. Solids, 240 (1998) 144.

[17] B. V. R. Chowdari, K. I. Tan,W.T. Chia and R. Goxalakrishnan, J. Non-Cryst. Solids, 119 (1990) 95.

[18] J. C. Buyn, B. H. Kim, K. S. Hong, H. J. Jung, S. W. Lee and A. A. Lzyneev, J. Non-Cryst. Solids, 190 (1995) 288.

[19] C. Daynand and M. S. Graw, J. Mater. Sci., 31 (1996) 1945.

[20] S.W. Martin, Eur. J. Solid Inorg. Chem., 28 (1) (1991) 163.

[21] L. Baia, D. Muresan, M. Baia, J. Popp and S. Simon, J. Vib. Spectrosc., 43 (2007) 313.

[22] S. N. Salman and H. A. El-Batal, J. Non-Cryst. Solids, 168 (1994) 179.

[23] Ayman bendary, Ph.D. Thesis, Al-Azhar Univ., (2014).

[24] Kulwant Singh, Harvinder Singh, Vishal Sharma, Rohila Nathuram, Atul Khanna, Rajesh Kumar, Surjit Singh Bhatti and Hari Singh Sahota, J. Nuclear Instruments and Methods in Physics Research B, 194 (2002) 1.

[25] K. A. Ali and A. G. Mostafa, Turkish J. Phys., 27 (3) (2003) 225.

[26] A. M. Zoulfakar, M. Sc. Thesis, Al-Azhar Univ., (2013). 


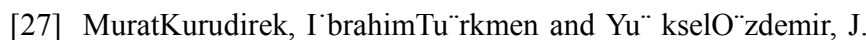
Radiation Physics and Chemistry, 78 (2009) 751.
[28] A. A. Ramadan, A. G. Mostafa, M. Y. Hassan, A. Z. Hussein and A. Y. Abdel-Hassib, Isotope and Rad. Res., 46 (1) (2014) 83 